\title{
FIXED POINT THEOREMS FOR SET-VALUED MAPPINGS IN $b$-METRIC SPACES
}

\author{
ALIREZA KAMEL MIRMOSTAFAEE \\ Center of Excellence in Analysis on Algebraic Structures \\ Department of Pure Mathematics, Ferdowsi University of Mashhad \\ P. O. Box 1159, Mashhad 91775, Mashhad, Iran \\ E-mail:mirmostafaei@um.ac.ir
}

\begin{abstract}
We will establish set-valued version of Suzuki's fixed point theorem when the underling space is a complete $b$-metric. Our method enable us to prove set-valued versions of Hardy-Rogers and Ĉirić fixed point theorems for $b$-metric spaces.
\end{abstract}

Key Words and Phrases: contraction-type mappings, fixed point theorems, set-valued functions. 2010 Mathematics Subject Classification: 37C25, 47H09, 47H10, $26 \mathrm{E} 25$.

Acknowledgements. I would like to express my sincere gratitude to the anonymous referee and editor for useful comments. This research was supported by a grant from Ferdowsi University of Mashhad (No. MP93323MIM).

\section{REFERENCES}

[1] S.M.A. Alemraninejad, Sh. Rezapour, N. Shahzad, On fixed point generalizations of Suzuki's method, Appl. Math. Letter, 24(2011), 1037-1040.

[2] J.P. Aubin, J. Siegel, Fixed points and stationary points of dissipative multivalued maps, Proc. Amer. Math. Soc., 78(1980), 391-398.

[3] H. Aydi, M. Bota, E. Karapinar, S. Mitrovic, A fixed point theorem for set-valued quasicontractions in b-metric spaces, Fixed Point Theory Appl., (2012), 2012:88.

[4] S. Banach, Sur les opérations dans les ensemble abstraits et leur application aux équations intégrales, Fund. Mat., 3(1922), 133-181.

[5] Lj.B. Ćirić, A generalization of Banach's contraction principle, Proc. Amer. Math., 45(1974), 267-273.

[6] A. Constantin, A random fixed point theorem for multifunctions, Stoch. Anal. Appl., 12(1994), 65-73.

[7] S. Czerwik, Contraction mappings in b-metric spaces, Acta Math. Inform. Univ. Ostraviensis, 1(1995), 5-11.

[8] A.H. Frink, Generalization of the $G_{\delta}$-property of complete metric spaces, Bull. Amer. Math. Soc., 43(1937), 133-142.

[9] G. Gruenhage, Generalized Metric Spaces, Handbook of Set-Theoretic Topology, North-Holland, Amsterdam, 1984, 423-501.

[10] G. Hardy, T. Rogers, A generalization of fixed point theorem of Reich, Canad. Math. Bull., 16(1973), 201-206.

[11] M. Kikkawa, T. Suzuki, Three fixed point theorems for generalized contractions with constants in complete metric spaces, Nonlinear Anal., 69(2008), 2942-2949. 
[12] G. Mot, A. Petruşel, Fixed point theory for a new type of contractive multivalued operators, Nonlinear Anal., 70(2009), 3371-3377.

[13] M. Maschler, B. Peleg, Stable sets and stable points of set-valued dynamic systems with applications to game theory, SIAM J. Control Optim., 14(1976), 985-995.

[14] S.B. Nadler, Jr., Multi-valued contraction mappings, Pacific J. Math., 30(1969), 475-488.

[15] T. Suzuki, A generalized Banach contraction principle that characterizes metric completeness, Proc. Amer. Math. Soc., 136(2008), 1861-1869.

[16] H. Yingtaweesittikul, Suzuki type fixed point theorems for generalized multivalued mappins in b-metric spaces, Fixed Point Theory Appl., 2013, 2013:215.

Received: May 26, 2014; Accepted: March 23, 2015. 
